OPEN ACCESS

Edited by:

Shourong Shi,

Poultry Institute, Chinese Academy of Agricultural Sciences (CAAS), China

Reviewed by:

Siaka Seriba Diarra, University of the South Pacific, Fiji

Yueping Chen Nanjing Agricultural University, China

*Correspondence:

Yu Yang

345605203@qq.com

Specialty section:

This article was submitted to Animal Nutrition and Metabolism, a section of the journal

Frontiers in Veterinary Science

Received: 20 May 2021 Accepted: 16 September 2021

Published: 21 October 2021

Citation:

Wang R, Bai Y, Yang Y, Wu XT and Li RR (2021) A Comparison of Production Performance, Egg Quality, and Cecal Microbiota in Laying Hens Receiving Graded Levels of Vitamin

B12. Front. Vet. Sci. 8:712183.

doi: 10.3389/fvets.2021.712183

\section{A Comparison of Production Performance, Egg Quality, and Cecal Microbiota in Laying Hens Receiving Graded Levels of Vitamin $\mathbf{B}_{\mathbf{1 2}}$}

\author{
Rui Wang ${ }^{1,2}$, Yan Bai ${ }^{1}$, Yu Yang ${ }^{1 *}$, Xiaotian $W u^{1}$ and Ruirui $L i^{1}$ \\ ${ }^{1}$ Laboratory of Poultry Production, College of Animal Science, Shanxi Agricultural University, Taigu, China, ${ }^{2}$ Department of \\ Life Sciences, Luliang University, Luliang, China
}

The objective of the study was to investigate the effect of fortified diets with standard vs. high levels of vitamin $\mathrm{B}_{12}$ on cecal microbiota composition, production performance, and eggshell quality of laying hens. Dietary treatments consisted of a basal diet with no supplementation of vitamin $B_{12}$ or supplemented with 25,100 , and $400 \mu \mathrm{g} / \mathrm{kg}$ vitamin $B_{12}$, respectively. A total of 432 laying hens were randomly assigned to four treatments with six replicates per treatment. No significant effect of dietary treatments on the production performance of hens was detected. The shell thickness of eggs from hens fed diet supplemented with $100 \mu \mathrm{g} / \mathrm{kg}$ of vitamin $\mathrm{B}_{12}$ was higher $(P<0.01)$ than that of eggs from hens fed control diet or supplemented with $25 \mu \mathrm{g} / \mathrm{kg}$ vitamin $B_{12}$. The shell percentage of eggs from hens fed diet supplemented with $400 \mu \mathrm{g} / \mathrm{kg}$ of vitamin $\mathrm{B}_{12}$ was higher $(P<0.01)$ than that of eggs from hens fed other treatment diets. Dietary vitamin $\mathrm{B}_{12}$ did not modulate diversity of the cecal microbiota of the layers. At genus level, the cecal content from layers fed diet with supplemental level of 100 or $400 \mu \mathrm{g} / \mathrm{kg}$ of vitamin $\mathrm{B}_{12}$ had higher $(P<0.01)$ abundance of Faecalibacterium and lower $(P<0.05)$ abundance of Acinetobacter compared with the cecal content from layers fed other two diets. The abundance of Lactobacillus in the cecal samples from layers fed $100 \mu \mathrm{g} / \mathrm{kg}$ of supplemental level of vitamin $B_{12}$ was higher $(P<0.05)$ than that from layers fed other three diets. The abundance of Butyricicoccus was higher $(P<0.05)$, while Bilophila was lower $(P<0.05)$ in the cecal content of layers fed $400 \mu \mathrm{g} / \mathrm{kg}$ of vitamin $B_{12}$ diet compared with those from layers fed other three diets. The results of PICRUSt analysis indicated that 10 predicted metabolic functions of the cecal microbial communities were positively correlated to dietary vitamin $\mathrm{B}_{12}$ level. Overall, dietary supplementation of 100 or $400 \mu \mathrm{g} / \mathrm{kg}$ of vitamin $\mathrm{B}_{12}$ had equivalent effects and caused the significant change in composition and metabolic functions of cecal microorganisms, which could positively impact eggshell quality, metabolism, and gut health of laying hens.

Keywords: vitamin $B_{12}$, laying hens, production performance, eggshell quality, cecal microbiota 


\section{INTRODUCTION}

Vitamin $B_{12}$ is one of essential $B$ vitamins required by humans and animals. Since it is involved in nucleic acid synthesis, carbohydrate and fat metabolism, and methyl synthesis, the deficiency of vitamin $B_{12}$ will cause anemia, muscle weakness, severe neurologic problems, and many other symptoms in humans and animals (1-6). In laying hens, numerous studies indicated that vitamin $B_{12}$ is required for optimal egg production, egg weight, and hen weight (7-11). Today, vitamins are commonly over fed in poultry feed to give safety margin for the deterioration of many vitamins during feed processing and storage (12-14). Also, vitamin-enriched eggs produced through supplementing extremely a high level of vitamins of interest to the layer diet for human consumption have been widely accepted (15-20). Subsequently, a significant portion of vitamins that was not absorbed in the small intestine of layers could reach the hind gut and affect the microbiota composition of the cecum. Giannella et al. reported that excess vitamin $B_{12}$ in the intestine changed the gut microbiome composition and caused the overgrowth of intestinal bacterial (21). Degnan et al. found that the competition and exchange of vitamin $\mathrm{B}_{12}$ among microbes can regulate the gut microcommunity (22). It was documented that vitamin $B_{12}$ and some other $B$ vitamins changed the metabolism of microbiota, promoted bacterial colonization in the gut, and modulated bacterial virulence and the host defense to the pathogen infection (2325). Results from in vitro and in vivo trials indicated that vitamin $B_{12}$ was essential for some enteropathogens to utilize ethanolamine, which enhanced Salmonella typhimurium growth and its virulence gene expression (26-29). Xu et al. indicated that vitamin $B_{12}$ supplementation changed microbial composition and increased the amount of short-chain fatty acids in an in vitro colon simulation (30).

Thus far, not much information is available for the link between high dietary vitamin $B_{12}$ and the intestinal microbiota composition in poultry. Therefore, the purpose of the current study was to investigate the effect of fortified diets with standard vs. high levels of vitamin $\mathrm{B}_{12}$ on cecal microbiota composition and production performance of laying hens.

\section{METHODS AND MATERIALS}

All experimental procedures were carried out in accordance with the Guidelines of the Shanxi Agricultural University Animal Experiment Ethics Committee, and the license number was SXAU-EAW-2017-002Chi.001. The experiment was performed in the Animal Production Laboratory of Shanxi Agricultural University and Xingmin Animal Husbandry Industry Cooperative located in Taigu District of Jinzhong City.

\section{Animals, Diets, and Experimental Design}

Based on a single-factor experimental design, a total of 432 healthy Jinghong No. 1 laying hens with the same initial body weight (BW) at 30 weeks of age were randomly assigned to four dietary treatments to give six replicate cages of three hens per cage. Dietary treatments included (1) corn soybean
TABLE 1 | Ingredients and composition of the basal diet (as fed basis).

\begin{tabular}{lclc}
\hline Ingredient & $\%$ & Nutrient $^{\mathbf{c}}$ & Value \\
\hline Corn & 64.50 & Metabolizable energy (MJ/kg) & 11.08 \\
Soybean meal & 21.00 & Crude protein (\%) & 16.46 \\
Cottonseed meal & 1.00 & Crude fiber (\%) & 3.00 \\
Linseed meal & 2.00 & Ether extract (\%) & 2.89 \\
Limestone & 9.66 & Ash (\%) & 12.61 \\
NaCl & 0.30 & Calcium (\%) & 3.51 \\
DL-methionine (98\%) & 0.40 & Total phosphorus (\%) & 0.50 \\
L-Lysine. $\mathrm{H}_{2} \mathrm{SO}_{4}(70 \%)$ & 0.04 & Available phosphorus (\%) & 0.22 \\
Choline chloride (50\%) & 0.11 & Methionine (\%) & 0.39 \\
Vitamin premix & 0.04 & Lysine (\%) & 0.78 \\
Mineral premix & 0.20 & Threonine (\%) & 0.58 \\
Calcium hydrophosphate & 1.00 & Methionine + Cysteine (\%) & 0.66 \\
Phytase (5,000 IU/g) & 0.02 & & \\
Total & 100.00 & & \\
\hline
\end{tabular}

a Supplied per kg diet: VA 14,400 IU, VD $D_{3} 54,00 \mathrm{IU}, V K_{3} 3.2 \mathrm{mg}, V E 32 \mathrm{mg}, V B_{1} 2.4 \mathrm{mg}$, $V B_{2} 10 \mathrm{mg}, V B_{6} 4 \mathrm{mg}$, folate $1 \mathrm{mg}$, nicotinic acid $48 \mathrm{mg}$, pantothenic acid $14 \mathrm{mg}$, and biotin $0.16 \mathrm{mg}$.

${ }^{b}$ Supplied per kg diet: $\mathrm{Cu}$ (as copper sulfate) $8 \mathrm{mg}, \mathrm{Fe}$ (as ferrous sulfate) $50 \mathrm{mg}, \mathrm{Mn}$ (as manganese sulfate) $100 \mathrm{mg}$, Zn (as zinc sulfate) $90 \mathrm{mg}$, I (as potassium iodide) $0.40 \mathrm{mg}$, Se (as sodium selenite) $0.36 \mathrm{mg}$, and Co (as cobalt sulfate) $0.26 \mathrm{mg}$.

${ }^{c}$ The values of metabolizable energy, available phosphorus, and amino acids are calculated, and others are measured values.

meal basal (basal) diet with no supplementation of vitamin $B_{12}$ (B0), (2) basal diet supplemented with $25 \mu \mathrm{g} / \mathrm{kg}$ of vitamin $\mathrm{B}_{12}$ (B25), (3) basal diet supplemented with $100 \mu \mathrm{g} / \mathrm{kg}$ of vitamin $\mathrm{B}_{12}$ (B100), and (4) basal diet supplemented with $400 \mu \mathrm{g} / \mathrm{kg}$ vitamin $\mathrm{B}_{12}$ (B400). The commercial product used in this trial contained $1 \%$ vitamin $B_{12}$ and was provided by Hebei Yuxing Bio-Engineering Co. Ltd. No vitamin $B_{12}$ was detected in the basal diet by using high-performance liquid chromatography. This is because vitamin $B_{12}$ is well-known to be the sole vitamin that is absent from plant-based feed sources. Three dietary supplemental levels of vitamin $B_{12}$ included one standard level of $25 \mu \mathrm{g} / \mathrm{kg}$ recommended by breeders and vitamin-producing companies $(31,32)$, and two $(100$ or $400 \mu \mathrm{g} / \mathrm{kg})$ high levels were used for producing vitamin $\mathrm{B}_{12}$-enriched eggs $(15,16)$. Other nutrient level of basal diet was designed based on the NRC recommendation (33). The composition and calculated nutrient level of basal diet are listed in Table $\mathbf{1}$.

The experimental chicken coop was completely enclosed with the stainless-steel galvanized cages of $47 * 37 * 38 \mathrm{~cm}$ in size. In a 14-day pretrial period, all laying hens were fed a basal diet. Then the treatment diets were provided to the laying hens for another 42 days. The layers were free to eat feed and drink water during the entire pretrial and trial periods. The daily light exposure was $16 \mathrm{~h}$ with an intensity not $<15 \mathrm{~lx} / \mathrm{m}^{2}$.

\section{The Assay of Production Performance, Egg Quality, and Serum Indicators of Laying Hens}

Hens in each replicate were weighed in-group at the start and at the end of the experiment to evaluate the BW change. Egg 
number, egg weight, and dead birds were recorded daily, whereas feed consumption was recorded weekly to calculate hen day egg production (\%), feed intake (g/hen/day), egg mass (g/day), and feed conversion ratio (feed/egg mass).

A total of 18 egg samples (three eggs per replicate) were taken weekly in a 6-week trial period to do the analysis of egg weight and eggshell quality. Egg diameter was measured with a digital display vernier caliper (S102-101-101, SMCT, Shanghai). Eggshell strength was evaluated using an Egg Force Reader (EFR01, Orka Food Technology Ltd., Israel). Eggshell thickness was measured on the large end, equatorial region, and small end, respectively, using an eggshell thickness gauge (Robotmation Co., Ltd., Tokyo, Japan), and the average value was calculated as the eggshell thickness measurement. The egg weight, egg yolk color, and Haugh unit (HU) were evaluated using an Egg Analyzer (EA-01, Orka Food Technology Ltd., Israel). Egg white and yolk were separated carefully, then the egg yolk and eggshell were weighed, and the ratio of the egg yolk, egg white, and eggshell was calculated.

Blood samples were taken from six hens per treatment (one bird per cage) to test the biochemical indicators of serum. Vitamin $\mathrm{B}_{12}$, progesterone, and estrogen levels were measured using enzyme-linked immunoassay kit (Shanghai Hushen Biological Technology Co., Ltd., China). Total cholesterol (TC) and triglyceride (TG) levels were measured using GPO-PAP (NanJing JianCheng Bioengineering Institute, China).

\section{The Assay of Cecal Microbiome}

At the end of the experiment, one bird with a BW close to the mean BW of each cage was euthanized by cervical dislocation to collect the cecal content. A total of six samples per treatment were collected. After collection, the samples were immediately frozen by liquid nitrogen and preserved at $-80^{\circ} \mathrm{C}$ until analysis. The frozen samples were used for isolation of metagenomic DNA.

\section{DNA Extraction}

Total bacterial genomic DNA samples were extracted using the Fast DNA SPIN extraction kits (MP Biomedicals, Santa Ana, CA, USA), following the instructions of the manufacturer, and stored at $-20^{\circ} \mathrm{C}$ prior to further analysis. The quantity and quality of extracted DNAs were measured using a NanoDrop ND1000 spectrophotometer (Thermo Fisher scientific, Waltham, MA, USA) and agarose gel electrophoresis, respectively. 16S rDNA amplicon pyrosequencing PCR amplification of the bacterial 16S rRNA gene V3-V4 region was performed using the forward primer $338 \mathrm{~F}\left(5^{\prime}\right.$-ACTCCTACGGGAGGCAGCA-3') and the reverse primer 806 $\left(5^{\prime}\right.$-GGACTACHVGGGTWTCTAAT$\left.3^{\prime}\right)$. Sample-specific 7-bp barcodes were incorporated into the primers for multiplex sequencing. The PCR components contained $5 \mu$ l of Q5 reaction buffer $(5 \times), 5 \mu$ of Q5 HighFidelity GC buffer $(5 \times), 0.25 \mu \mathrm{l}$ of Q5 High-Fidelity DNA Polymerase $(5 \mathrm{U} / \mu \mathrm{l}), 2 \mu \mathrm{l}(2.5 \mathrm{mM})$ of dNTPs, $1 \mu \mathrm{l}(10 \mu \mathrm{M})$ of each forward and reverse primer, $2 \mu$ of DNA template, and 8.75 $\mu \mathrm{l}$ of $\mathrm{ddH}_{2} \mathrm{O}$.

Thermal cycling included initial denaturation at $98^{\circ} \mathrm{C}$ for $2 \mathrm{~min}$, followed by 25 cycles consisting of denaturation at $98^{\circ} \mathrm{C}$ for $15 \mathrm{~s}$, annealing at $55^{\circ} \mathrm{C}$ for $30 \mathrm{~s}$, and extension at $72^{\circ} \mathrm{C}$ for
$30 \mathrm{~s}$, with a final extension of $5 \mathrm{~min}$ at $72^{\circ} \mathrm{C}$. PCR amplicons were purified with Agencourt AMPure Beads (Beckman Coulter, Indianapolis, IN, USA) and quantified using the PicoGreen dsDNA Assay Kit (Invitrogen, Carlsbad, CA, USA). After the individual quantification step, amplicons were pooled in equal amounts, and paired-end 2,300-bp sequencing was performed using the Illlumina MiSeq platform with MiSeq Reagent Kit v3 at Shanghai Personal Biotechnology Co., Ltd. (Shanghai, China).

\section{Sequence Analysis}

The Quantitative Insights Into Microbial Ecology (QIIME, v1.8.0) pipeline was employed to process the sequencing data, as previously described (34). Briefly, raw sequencing reads with exact matches to the barcodes were assigned to respective samples and identified as valid sequences. The low-quality sequences were filtered through following criteria $(35,36)$ sequences that had a length of $<150 \mathrm{bp}$, sequences that had average Phred scores of $<20$, sequences that contained ambiguous bases, and sequences that contained mononucleotide repeats of $>8 \mathrm{bp}$. Paired-end reads were assembled using FLASH (37). After chimera detection, the remaining high-quality sequences were clustered into operational taxonomic units (OTUs) at $97 \%$ sequence identity by UCLUST (38). A representative sequence was selected from each OTU using default parameters. OTU taxonomic classification was conducted by BLAST searching the representative sequences set against the Greengenes Database (39) using the best hit (40).

\section{Bioinformatics and Statistical Analysis}

Sequence data analyses were mainly performed using QIIME and $\mathrm{R}$ packages (v3.2.0). OTU-level alpha diversity indices, such as Chaol richness estimator, ACE metric (Abundancebased Coverage Estimator), Shannon diversity index, and Simpson index, were calculated using the OTU table in QIIME. OTU-level ranked abundance curves were generated to compare the richness and evenness of OTUs among samples. Differences in the Unifrac distances for pairwise comparisons among groups were determined using Student's $t$-test and the Monte Carlo permutation test with 1,000 permutations. The taxonomy compositions and abundances were visualized using MEGAN (41) and GraPhlAn (42). Venn diagram was generated to visualize the shared and unique OTUs among samples or groups using R package "VennDiagram," based on the occurrence of OTUs across samples/groups regardless of their relative abundance (43). Taxa abundances at the phylum and genus levels were statistically compared among samples or groups by Metastats (44). Pattern Search was used to identify correlation between the microbial composition of cecal content and dietary supplemental level of vitamin $B_{12}$. Microbial functions were predicted by PICRUSt (phylogenetic investigation of communities by reconstruction of unobserved states), based on high-quality sequences (45). Correlation Heatmap was performed using the OmicStudio tools at https:// www.omicstudio.cn/tool.

Data were analyzed with one-way ANOVA by using Statistical Product and Service Solutions (SPSS) 22.0 (SPSS Inc., Chicago, IL, USA). The significant difference of means among treatment 
TABLE 2 | Effects of dietary supplementation of vitamin $B_{12}$ on the production performance of laying hens ${ }^{*}$.

\begin{tabular}{|c|c|c|c|c|c|c|c|}
\hline Items & & \multicolumn{4}{|c|}{ Vitamin $B_{12}$ level $(\mu \mathrm{g} / \mathrm{kg})$} & SEM & $P$-Value \\
\hline & Experimental period & 90.63 & 91.87 & 90.34 & 91.85 & 1.25 & 0.81 \\
\hline Feed intake (g/hen/day) & 122.1 & 124.9 & 123.3 & 123.3 & 2.18 & 0.91 & \\
\hline Feed conversion ratio (feed/egg mass) & 2.10 & 2.13 & 2.14 & 2.10 & 0.06 & 0.65 & \\
\hline Egg weight (g) & 64.22 & 63.93 & 63.92 & 64.01 & 0.67 & 0.60 & \\
\hline
\end{tabular}

${ }^{*}$ Data are expressed as the means and pooled standard error of the mean (SEM) $(n=6)$.

TABLE 3 | Effects of dietary supplementation of vitamin $B_{12}$ on the eggshell and egg quality*.

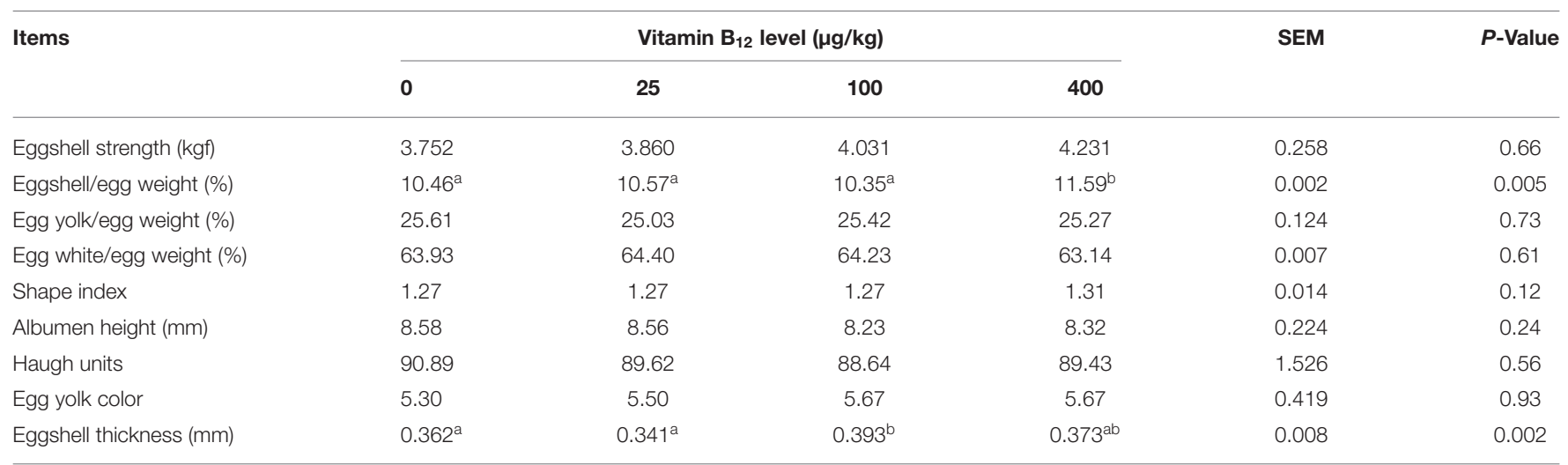

${ }^{*}$ Data are expressed as the means and pooled standard error of the mean (SEM) $(n=6)$.

${ }^{a, b}$ Means in the same row not sharing a common superscript differ significantly at $P<0.05$.

TABLE 4 | Effects of dietary supplementation of vitamin $B_{12}$ on the serum indicators of laying hens ${ }^{*}$.

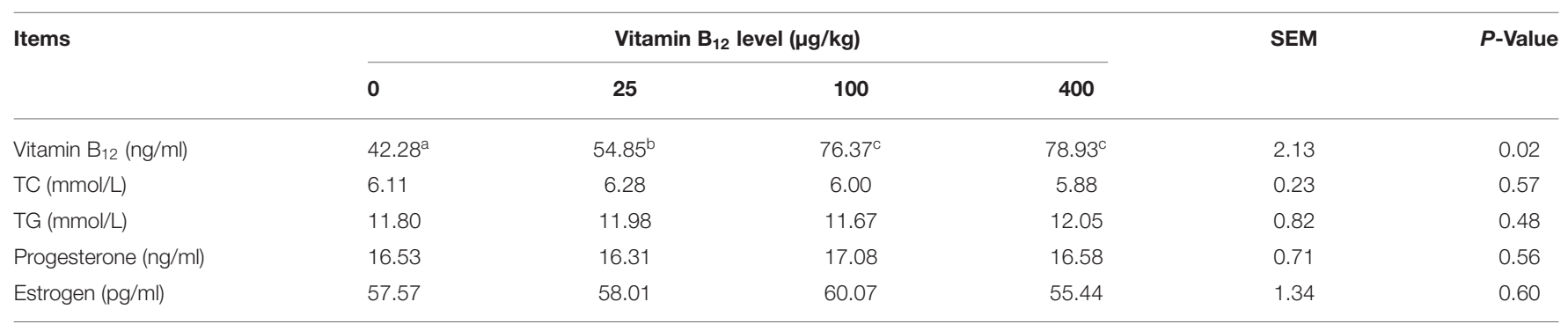

${ }^{*}$ Data are expressed as the means and pooled standard error of the mean (SEM) $(n=6)$.

$a, b, c$ Means in the same row not sharing a common superscript differ significantly at $P<0.05$.

groups was identified via Tukey's test. The significance was determined at $P<0.05$.

\section{RESULTS}

\section{Production Performance, Egg Quality, and Serum Indicators of Laying Hens}

Effects of dietary vitamin $\mathrm{B}_{12}$ on the production performance of laying hens are shown in Table 2. There was no significant difference among all treatments for egg production, feed intake, feed conversion ratio, egg mass, and egg weight $(P>0.05)$.
Table 3 lists the effect of dietary vitamin $B_{12}$ on egg quality parameters. The shell percentage of eggs from hens fed diet supplemented with $400 \mu \mathrm{g} / \mathrm{kg}$ of vitamin $\mathrm{B}_{12}$ was higher $(P<$ 0.05 ) than that of eggs from hens fed other treatment diets. The shell thickness of eggs from hens fed diet supplemented with 100 $\mu \mathrm{g} / \mathrm{kg}$ of vitamin $\mathrm{B}_{12}$ was higher $(P<0.05)$ than that of eggs from hens fed control diet or supplemented with $25 \mu \mathrm{g} / \mathrm{kg}$ of vitamin $B_{12}$. No significant effect of dietary treatments on other egg quality parameters was detected $(P>0.05)$.

The biochemical indicators of serum are listed in Table 4 . The vitamin $B_{12}$ concentration of serum from hens fed diet with a 
supplementation of $25 \mu \mathrm{g} / \mathrm{kg}$ of vitamin $\mathrm{B}_{12}$ was higher $(P<0.05)$ than that from hens fed diet with no supplementation of vitamin $\mathrm{B}_{12}$, but lower $(P<0.05)$ than that from hens fed other two diets with high supplemental levels of vitamin $B_{12}$. There was no significant difference among all treatments for other parameters.

\section{Cecal Microbiota Composition}

To explore the diversity of the cecal microbiota of layers after dietary vitamin $\mathrm{B}_{12}$ supplementation, the composition and species distribution of the cecal microbiota were investigated by 16S rRNA gene sequencing. After removal of the questioning sequences, a total sequencing quantity was 952,855 that was from 24 samples of cecal content with an average of 39,702 sequences per sample (range from 27,769 to 50,808) for subsequent analysis. A total of 4,386 OTUs after streamlining was characterized into different taxonomic levels including phylum, class, order, family, genus, and species based on Green gene database through QIIME with a $97 \%$ species similarity. Venn diagram analysis showed that 1,927 OTUs were shared among the four dietary treatment

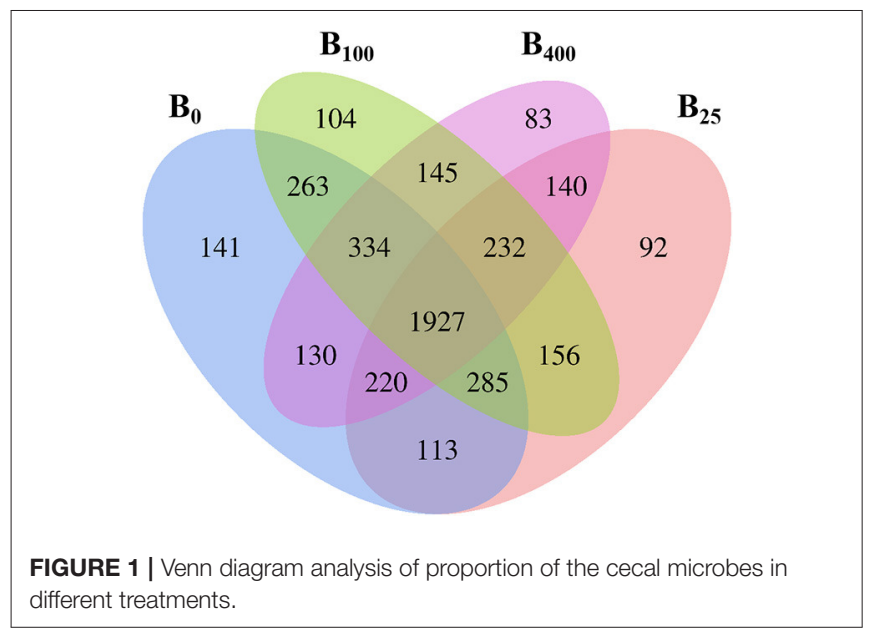

FIGURE 1 | Venn diagram analysis of proportion of the cecal microbes in different treatments. groups (Figure 1). There were 3,413, 3,165, 3,446, and 3,211 OTUs in treatments B0, B25, B100, and B400, respectively. These results indicated that dietary vitamin $\mathrm{B}_{12}$ did not modulate diversity of the cecal microbiota of the layers. However, there were $141,92,104$, and 83 OUTs that were uniquely identified in four different treatments.

The rarefaction curves and species accumulation curve (Figures 2A,B) for each sample leveled off as the number of sequences increased in all four treatment groups indicating that the samples analyzed had sufficient sequence coverage to accurately describe the bacterial composition of the cecal content in this study.

The alpha diversity of microbiota in the cecal content, including species diversity (Shannon and Simpson indices) and richness (ACE and Chao 1 indices), is shown in Table 5. There was no significant difference among all treatments for these indices, although the group with no vitamin $\mathrm{B}_{12}$ supplementation tended to have higher values of ACE and Chaol.

Figure $\mathbf{3 A}$ and Supplementary Table $\mathbf{1}$ demonstrated the microbial composition of cecal content from four dietary treatments in the phylum level. The results indicated that cecal microbiota of layers was mainly composed of Firmicutes, Bacteroidetes, and Proteobacteria accounting for about 94\%, with Firmicutes being the predominant phylum (>52). A numerical shift in the proportion of Bacteroidetes and Proteobacteria to Firmicutes was observed when high-level vitamin $B_{12}$ (100 or 400 $\mu \mathrm{g} / \mathrm{kg}$ ) was included in the diets. The proportion of Firmicutes, Actinobacteria, Deferribacteres, WPS_2, and Spirochaetes is positively correlated, and the proportion of Elusimicrobia, Thermi, TM7, Cyanobacteria, Lentisphaerae, Planctomycetes, Proteobacteria, Fusobacteria, Verrucomicrobia, Synergistetes, and Bacteroidetes is negatively correlated with the supplemental level of vitamin $\mathrm{B}_{12}$ (Figure 3C).

At genus level, a total of 173 species of bacteria in the cecal content of laying hens was observed in this trial, among which 17 genera had the relative abundance of more than 1\% (Figure 3B; Supplementary Table 2). Pattern Search results
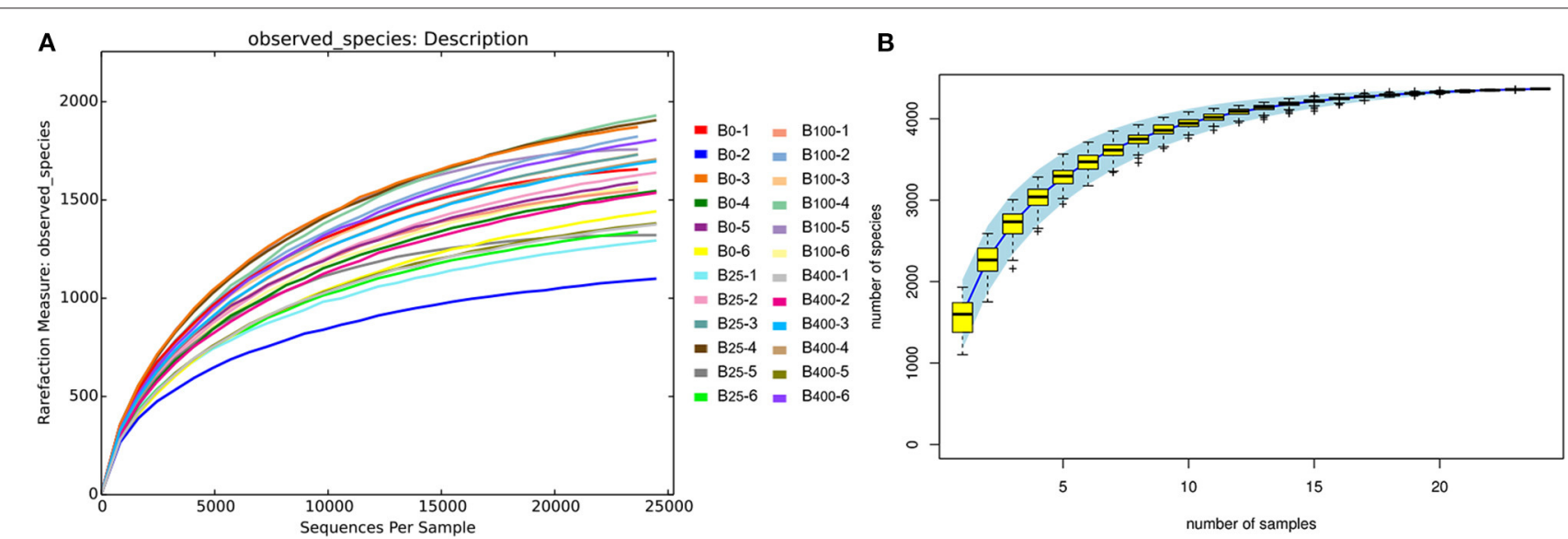

FIGURE 2 | (A) Rarefaction curves and (B) species accumulation curve diagram analysis of proportion of the cecal microbes in different treatments. 
TABLE 5 | Effects of dietary supplementation of vitamin $B_{12}$ on the cecal microbial diversity in laying hens ${ }^{*}$.

\begin{tabular}{|c|c|c|c|c|c|c|}
\hline \multirow[t]{2}{*}{ Items } & \multicolumn{4}{|c|}{ Vitamin $B_{12}$ level $(\mu \mathrm{g} / \mathrm{kg})$} & \multirow[t]{2}{*}{ SEM } & \multirow[t]{2}{*}{$P$-value } \\
\hline & 0 & 25 & 100 & 400 & & \\
\hline Simpson & 0.984 & 0.987 & 0.985 & 0.985 & 0.002 & 0.50 \\
\hline Shannon & 8.14 & 8.14 & 8.03 & 7.91 & 0.12 & 0.51 \\
\hline Chao1 & 1955.8 & 1701.2 & 1696.5 & 1798.2 & 104.1 & 0.36 \\
\hline ACE & 2013.8 & 1768.8 & 1767.8 & 1885.8 & 114.2 & 0.40 \\
\hline
\end{tabular}

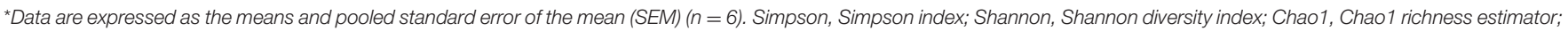
ACE, abundance-based coverage estimator metric.

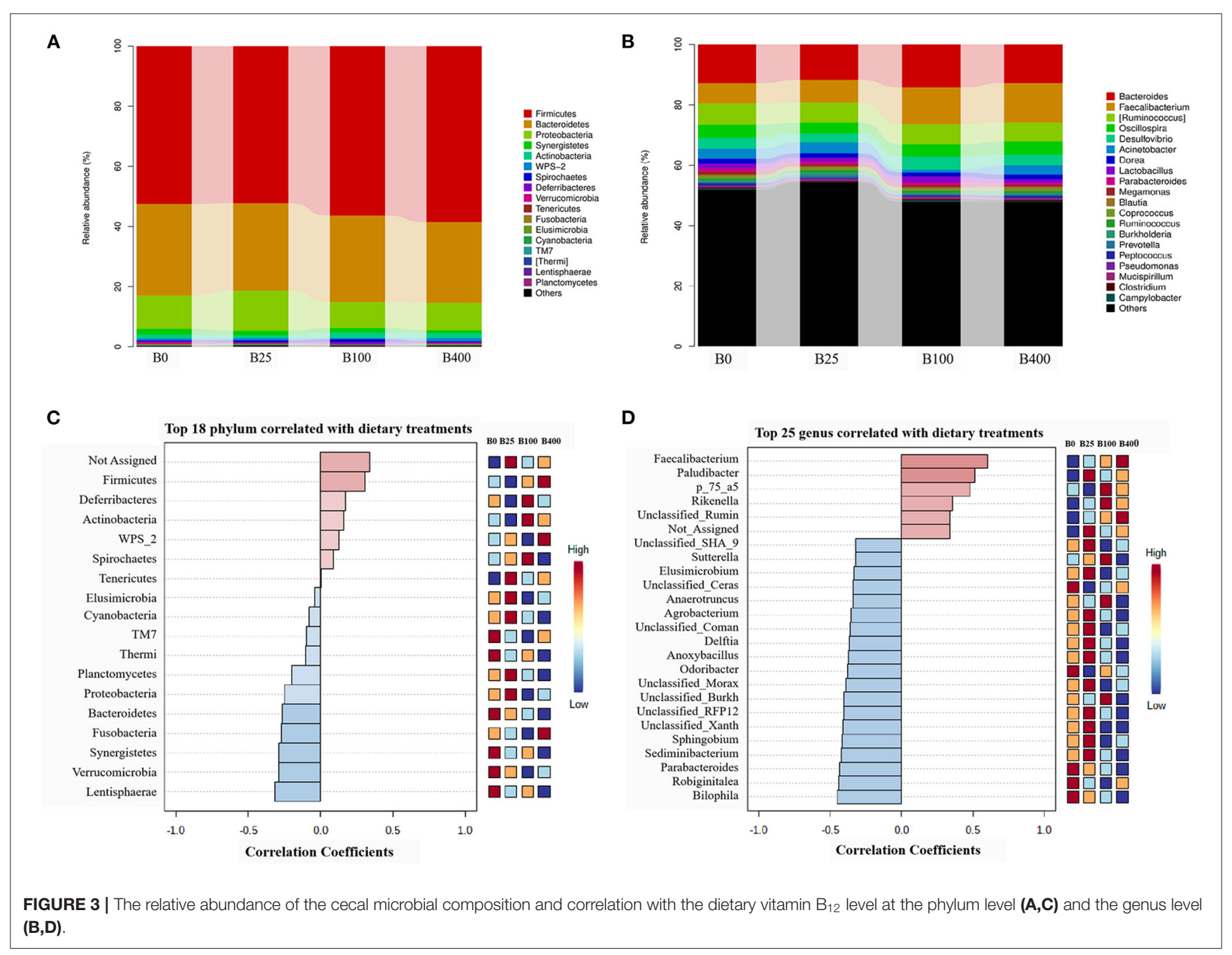

indicated that the abundance of Butyricicoccus, Faecalibacterium, Paludibacter, p_75_a5, and Unclassified_Ruminococcaceae has a positive correlation, and the abundance of the other 20 bacteria has a negative correlation with the dietary supplemental level of vitamin $\mathrm{B}_{12}$ (Figure $\left.3 \mathrm{D}\right)$.

As shown in Figure 4, the cecal content from layers fed a diet with supplemental level of 100 or $400 \mu \mathrm{g} / \mathrm{kg}$ of vitamin $\mathrm{B}_{12}$ had higher $(P<0.01)$ abundance of Faecalibacterium and lower $(P<0.05)$ abundance of Acinetobacter compared with the cecal content from layers fed other two diets. The abundance of Lactobacillus in the cecal samples from layers fed $100 \mu \mathrm{g} / \mathrm{kg}$ of a supplemental level of vitamin $B_{12}$ was higher $(P<0.05)$ than that from layers fed with the other three diets. The abundance of Paraprevotella, Blvii28, Perlucidibaca, and Succinatimonas in the cecal content of the layers fed diets supplemented with 25 or $100 \mu \mathrm{g} / \mathrm{kg}$ of vitamin $\mathrm{B}_{12}$ was higher $(P<0.05)$ than that from 


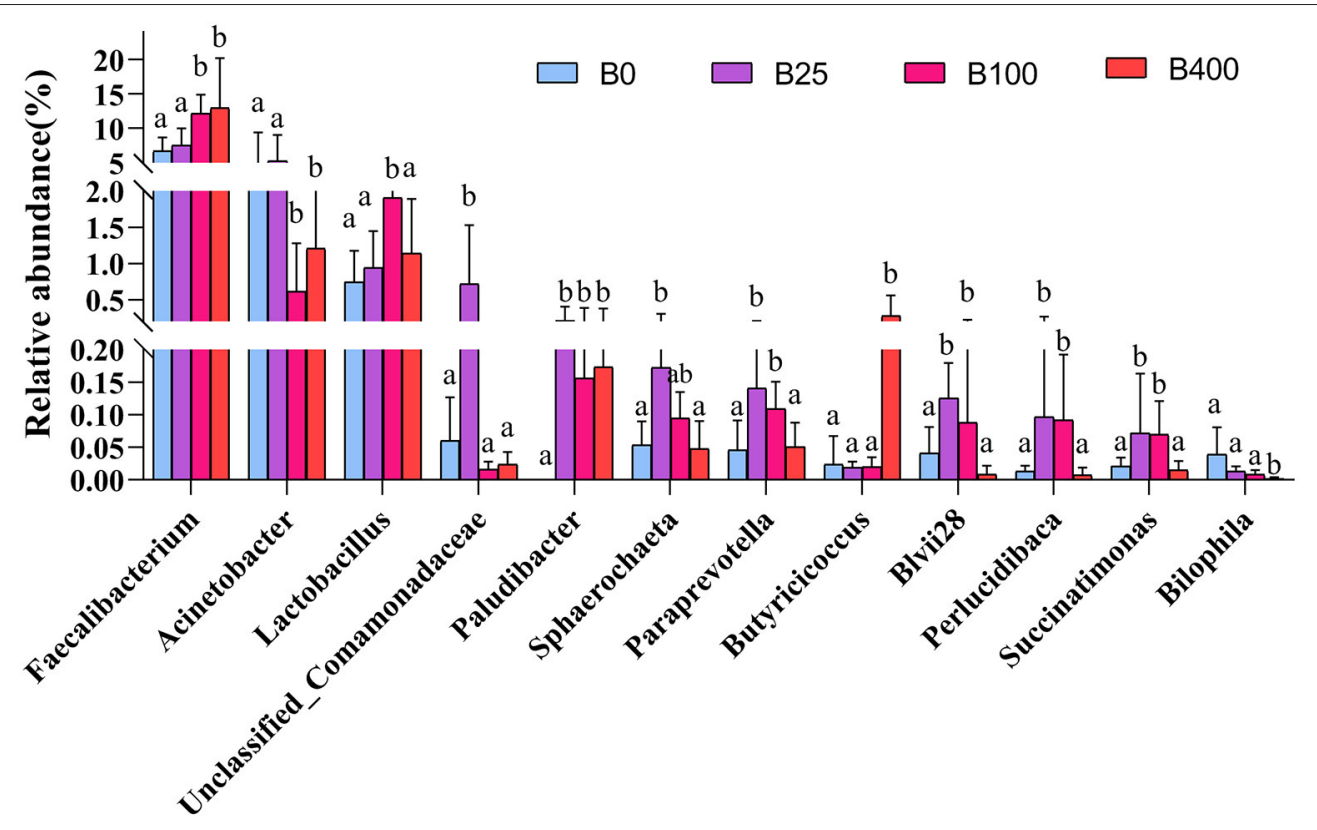

FIGURE 4 | The relative abundance of cecal microbiota of layers fed diets with different levels of vitamin $B_{12}$ at genus level only statistically significant differences are shown. Bars with different superscript letters were significantly different $(P<0.05)$.

the layers fed with the other two diets. It was worth noting that Paludibacter was not detected in the cecal content of layers fed a diet with no supplementation of vitamin $B_{12}$. The abundance of Butyricicoccus was significantly higher, while Bilophila was significantly lower in the cecal content of layers fed $400 \mu \mathrm{g} / \mathrm{kg}$ of vitamin $\mathrm{B}_{12}$ diet compared with that from layers fed with the other three diets.

\section{Functional Prediction of the Gut Microbiota}

In order to get the predicted metabolic functions of the cecal microbial communities from different treatments, PICRUSt analysis was performed. The results are shown in Figure 5. Ten predicted metabolic functions of the cecal microbial communities were positively correlated with dietary vitamin $\mathrm{B}_{12}$ level $(P<0.05)$. These metabolic functions included (1) carbohydrate metabolism such as starch and sucrose metabolism, pentose and glucuronate interconversions, other glycan degradation, and galactose metabolism; (2) lipid metabolism such as sphingolipid metabolism and secondary bile acid biosynthesis; (3) biosynthesis of other secondary metabolites such as phenylpropanoid biosynthesis and flavone and flavonol biosynthesis; (4) other metabolisms such as polycyclic aromatic hydrocarbon degradation and biosynthesis and biodegradation of secondary metabolites. The cecal microbiota from layers fed a diet with $400 \mu \mathrm{g} / \mathrm{kg}$ of vitamin $\mathrm{B}_{12}$ increased all the predicted metabolic functions except flavone and flavonol biosynthesis.

Based on the results of Spearman's analysis (Figure 6), a positive correlation $(P<0.05)$ between the abundance of Acinetobacter in the cecal content and the biosynthesis and biodegradation of secondary metabolites and polycyclic aromatic hydrocarbon degradation was found. The abundance of Butyricicoccus and Paludibacter in the cecal content was positively correlated $(P<0.05)$ with carbohydrate and lipid metabolism. A negative correlation $(P<0.05)$ between the abundance of Bilophila in the cecal content and biosynthesis and biodegradation of secondary metabolites was observed. The abundance of Lactobacillus was positively correlated $(P<0.05)$ with flavone and flavonol biosynthesis.

\section{DISCUSSION}

The results from the current study showed no significant effect of dietary vitamin $\mathrm{B}_{12}$ levels on the production performance of laying hens including egg production, feed intake, and egg weight. Although the concentration of vitamin $\mathrm{B}_{12}$ in $\mathrm{B} 0$ is below the detectable limit, no negative impact on the production performance due to deficiency of vitamin $B_{12}$ was noticed. This is probably because the layers might get enough reservation of vitamin $B_{12}$ in the tissues from pretrial diets to support the need of production. The similar results were reported by other researchers (46-48). Kominato reported that 2-5 months may be needed to completely deplete hens of vitamin $\mathrm{B}_{12}$ stored in tissues (49). The high dietary levels of vitamin $B_{12}$ (100 or $400 \mu \mathrm{g} / \mathrm{kg}$ ) used in this trial did not affect the production performance of layers, but significantly increased the thickness and the percentage of eggshell. Leeson and Caston reported that a high dietary vitamin $\mathrm{B}_{12}$ had no effect on the egg production of laying hens (15). The improvement of eggshell quality is probably due to the change in microbiota and their metabolites in the gut. A positive correlation between the abundance of butyrateproducing bacterium and Lactobacillus in the cecal content and dietary vitamin $B_{12}$ level was found in this trail. Many studies indicated the beneficial effect of dietary inclusion of butyrate or probiotic including Lactobacillus on the eggshell quality (50-53). 


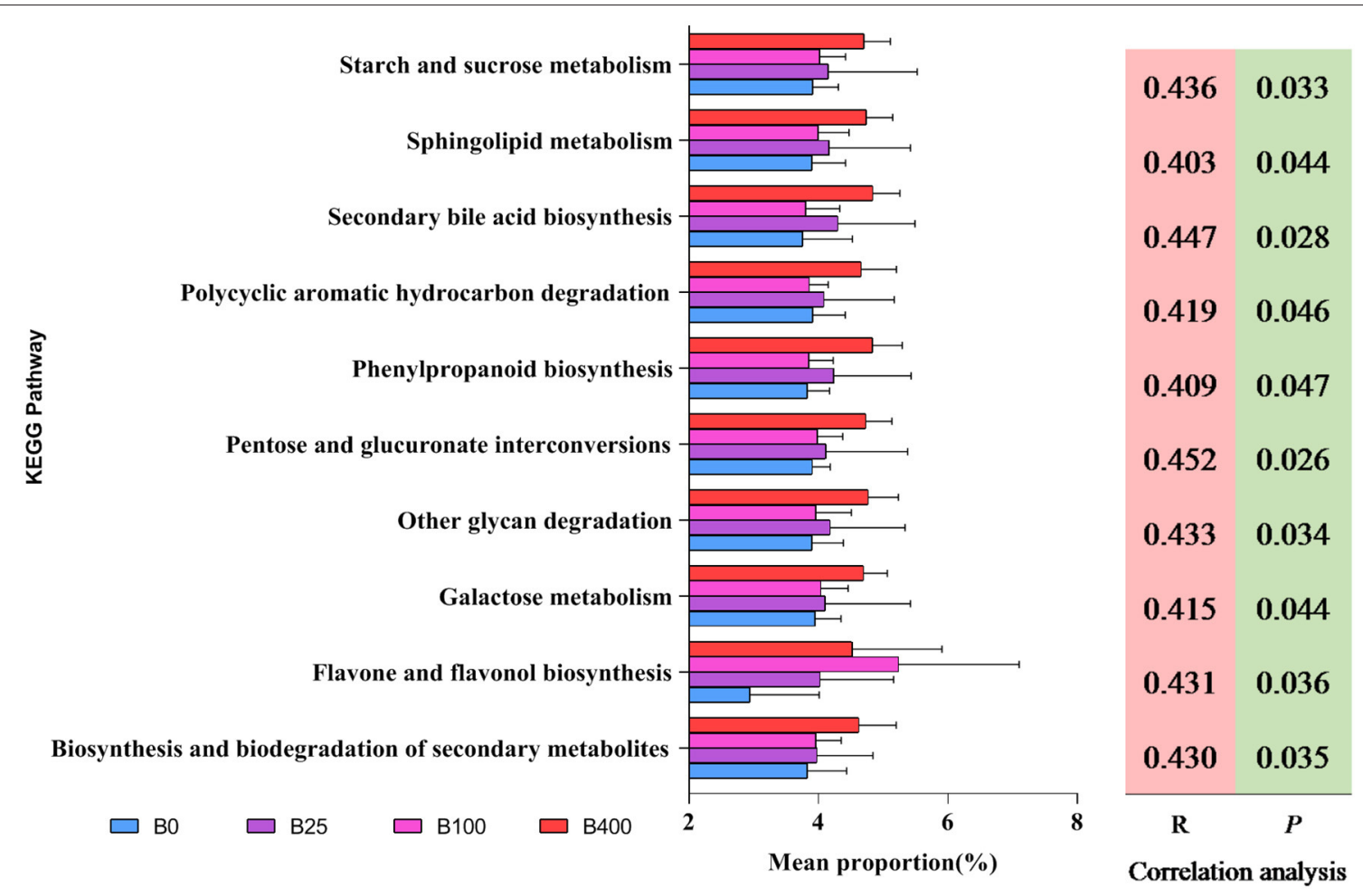

FIGURE 5 | The predicted metabolic attributes of cecal microbiota at genus level from different treatments.

Vitamin $\mathrm{B}_{12}$ is a critical nutrient for human beings, animals, as well as microbes. Studies indicated that dietary inclusion of vitamin $B_{12}$ increased the level of vitamin $B_{12}$ in the hind gut and modulated the structure and function of microbial communities in humans and mice $(22,54,55)$. In the current study, although different dietary levels of vitamin $\mathrm{B}_{12}$ did not alter the diversity of cecal microbiota of layer hens as evident by the similar $\alpha$-diversity index among different treatments, the community structure and abundance of the microbiota in the cecum were significantly changed. A positive correlation between dietary level of vitamin $\mathrm{B}_{12}$ and cecal abundance of Firmicutes was detected. Studies found that Firmicutes is one of the dominant microorganisms in the cecum of chicken, and the abundance of Firmicutes is beneficial to the health of the bird because of its anti-inflammatory effects (56-58). The negative correlation between the dietary level of vitamin $B_{12}$ and the richness of Bacteroidetes in the cecal content observed in this trial did not support the results reported by Kelly et al. and Wang $(55,59)$. The abundance changes in microbiota due to dietary vitamin $\mathrm{B}_{12}$ level could impact the energy metabolism of laying hens. This is based on some evidence showing the close relationship between the abundance of Firmicutes or Bacteroidetes and body fat accumulation in humans and some obesity-related parameters in mice $(60,61)$. However, further investigation is needed.

It is well-documented that butyrate can positively impact intestinal health through the synergistic effect of providing energy to the intestinal cell and anti-inflammatory effect (6264). Major butyrate-producing bacteria in the gastral intestinal tract included $F$. prasusnitzii in Faecalibacterium genus and Butyricoccus $(65,66)$. They all played a very important role in host intestinal health $(58,66-68)$. Results from the current study indicated that Faecalibacterium was the core genus in the cecum of laying hens and was positively correlated with dietary supplemental levels of vitamin $\mathrm{B}_{12}$, and dietary supplementation of high-level vitamin $B_{12}(100$ or $400 \mu \mathrm{g} / \mathrm{kg}$ ) increased the abundance of Butyricoccus. The increased abundance of Lactobacillus, Paraprevotella, Succinatimonas, Paludibacter, and Sphaerochaeta in the cecal content due to high dietary vitamin $\mathrm{B}_{12}(100$ or $400 \mu \mathrm{g} / \mathrm{kg})$ observed in this trial could also positively impact the gut health of laying hens. This is because bacteria in the gut, including Lactobacillus and Paraprevotella, have been proven to play an active and protective role in intestinal health of the host through producing antimicrobial molecules, competitive exclusion, and changing bile acid metabolism in the gut (69-71). Succinatimonas, Paludibacter, and Sphaerochaeta were found to produce volatile fatty acids including acetic acid, propionic acid, and succinic acid that could positively impact energy metabolism of the host and regulate hindgut $\mathrm{pH}$ to inhibit the growth of harmful bacteria (72-77). Dietary supplementation of high-level vitamin $\mathrm{B}_{12}$ depressed the richness of Acinetobacter and Bilophila that were inflammation-associated genera (78). The composition changes in cecal microbiota of laying hens found in this trial due to high dietary vitamin $\mathrm{B}_{12}$ was also significantly correlated to the predicted metabolism function of microbial communities in the cecum including carbohydrate, lipid, and 


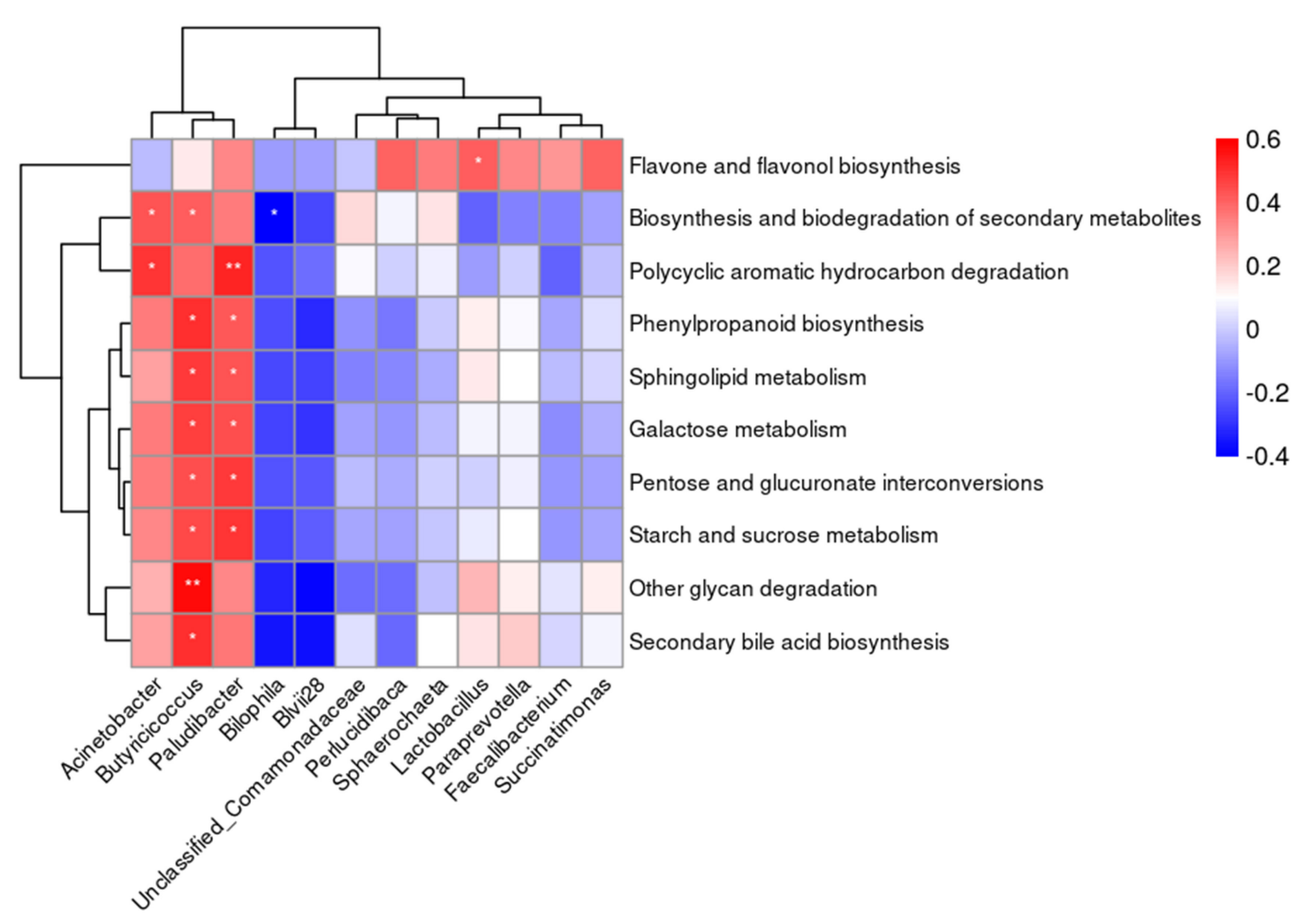

FIGURE 6 | The correlation heatmap between the abundance of microbiota at genus level in the cecal content and the predicted metabolic functions. ${ }^{\star} P<0.05$, ${ }^{\star \star} P<0.01$.

many other metabolisms. Similar results were reported by other researchers (79).

\section{CONCLUSIONS}

To our knowledge, this is the first trial to explore the relationship between high dietary levels of vitamin $\mathrm{B}_{12}$ and the cecal microbiota in laying hens. The results indicated that dietary supplementation of $100 \mu \mathrm{g} / \mathrm{kg}$ of vitamin $\mathrm{B}_{12}$ had equivalent effects with the supplemental level of $400 \mu \mathrm{g} / \mathrm{kg}$. Both levels caused a significant change in composition and metabolic functions of cecal microorganisms, which could positively impact eggshell quality, metabolism, and gut health of laying hens during peak production period. These findings provided the valuable information for the application of high supplemental levels of vitamin $B_{12}$ in the diet of laying hens for production or health purposes.

\section{DATA AVAILABILITY STATEMENT}

The datasets presented in this study can be found in online repositories. The names of the repository/repositories and accession number(s) can be found below: BioProject ID PRJNA732929.

\section{ETHICS STATEMENT}

All experimental procedures were carried out in accordance with the Guidelines of the Shanxi Agricultural University Animal Experiment Ethics Committee, and the license number was SXAU-EAW-2017-002Chi.001.

\section{AUTHOR CONTRIBUTIONS}

YY: conceptualized the study, supervised the study, was in charge of the project administration, and acquired the funding. RW: developed the methodology, performed the formal analysis and data curation, obtained the resources, and wrote and prepared the original draft. RRL and RW: conducted the investigation. RW, XTW, and YB wrote, reviewed, and edited the manuscript. All authors have read and agreed to the published version of the manuscript.

\section{FUNDING}

This research was funded by the 1331 Key Discipline Construction of Engineering Animal Husbandry of Shanxi Province (J202011315), Key Research and Development Project of Science and Technology (Agriculture) of Jinzhong City (Y182011), and Scientific and Technological 
Innovation Programs of Higher Education Institutions in Shanxi (2019L0959).

\section{ACKNOWLEDGMENTS}

We would like to thank relative personnel of Xingmin Animal Husbandry Cooperative (Taigu, China) for guidance in the feeding process. We would also

\section{REFERENCES}

1. Sahasrabudhe MR, Lakshminarayan Rao MV. Effect of Vitamin $B_{12}$ on the synthesis of protein and nucleic acids in the liver. Nature. (1951) 168:605-6. doi: 10.1038/168605b0

2. Guest JR, Friedman S, Woods DD, Smith EL, A. Methyl analogue of cobamide coenzyme in relation to methionine synthesis by bacteria. Nature. (1962) 195:340-2. doi: 10.1038/195340a0

3. Banerjee RV, Harder SR, Ragsdale SW, Matthews RG. Mechanism of reductive activation of cobalamin-dependent methionine synthase: an electron paramagnetic resonance spectroelectrochemical study. Biochemistry. (1990) 29:1129-35. doi: 10.1021/bi00457a005

4. Funada B, Tetsunori K, Tanaka N, Maekawa A, Mano H, Wada M. Change of the immune function in the rat vitamin $\mathrm{B}_{12}$ condition of depletion. Vitamins. (2002) 76:180.

5. Reynolds E. Vitamin $\mathrm{B}_{12}$, folic acid, and the nervous system. Lancet Neurol. (2006) 5:949-60. doi: 10.1016/S1474-4422(06)70598-1

6. Green R, Allen LH, Bjørke-Monsen AL, Brito A, Guéant JL, Miller JW. Vitamin $\mathrm{B}_{12}$ deficiency. Nat Rev Dis Primers. (2017) 3:17040. doi: $10.1038 / \mathrm{nrdp} .2017 .40$

7. Savage JE, Turner CW, Kempster HL,Hogan AG. The effects of vitamin $\mathrm{B}_{12}$ and thyroprotein on egg production, egg weight, shell quality and hatchability. Poult Sci. (1952) 31:22-30. doi: 10.3382/ps.0310022

8. Weberw GM. Improvement of flock productivity through supply of vitamins for higher laying performance and better egg quality. Worlds Poult Sci J. (2009) 65:443-58. doi: 10.1017/S0043933909000312

9. Kato RK, Bertechini AG, Fassani EJ, Santos CD, Dionizio MA, Fialho ET. Cobalt and vitamin $\mathrm{B}_{12}$ in diets for commercial laying hens on the second cycle of production. Braz J Poult Sci. (2003) 5:45-50. doi: 10.1590/S1516-635X2003000100006

10. Patel MB. Mcginnis J. The effect of levels of protein and vitamin $B_{12}$ in hen diets on egg production and hatchability of eggs and on livability and growth of chicks. Poult Sci. (1977) 56:45-53. doi: 10.3382/ps.0560045

11. El-Husseiny OM, Soliman AZM, Elsherif HMR. Influence of dietary methionine, folic acid and cyanocobalamin and their interactions on the performance of broiler breeder. Int J Poult Sci. (2018) 17:189-96. doi: 10.3923/ijps.2018.189.196

12. Scott ML. Effect of processing on the availability and nutritional value of vitamins. In: Scott ML, editor. Effect of Processing on the Nutritional Value of Feeds. Washington, DC: National Academy of Sciences (1972) p. 119-130.

13. Killeit V. The Stability of Vitamins-A Selection of Current Literature. Basel: F. Hoffmann-LaRoche Co. Ltd. (1988).

14. Coelho M. Fate of vitamins in premixes and feeds: vitamin stability. Feed Mgmt. (1991) 42:24-35.

15. Leeson S, Caston LJ. Vitamin enrichment of eggs. J Appl Poult Res. (2003) 12:24-6. doi: 10.1093/japr/12.1.24

16. Sahlin A, House JD. Enhancing the vitamin content of meat and eggs: implications for the human diet. Can J Anim Sci. (2006) 86:181-95. doi: $10.4141 / \mathrm{a} 05-060$

17. Halick JV, Reid BL, Brown CL, Couch JR. The vitamin $B_{12}$ content of egg yolks as influenced by oral and parenteral administration of the vitamin. J Nutr. (1953) 50:331-40. doi: 10.1093/jn/50.3.331

18. Denton CA, Kellogg WL, Sizemore JR, Lillie RJ. Effect of injecting and feeding vitamin $\mathrm{B}_{12}$ to hens on content of the vitamin in the egg and blood. J Nutr. (1954) 54:571-7. doi: 10.1093/jn/54.4.57 like to thank Editage (www.editage.cn) for English language editing.

\section{SUPPLEMENTARY MATERIAL}

The Supplementary Material for this article can be found online at: https://www.frontiersin.org/articles/10.3389/fvets. 2021.712183/full\#supplementary-material

19. Squires MW, Naber EC. Vitamin profiles of eggs as indicators of nutritional status in the laying hen: vitamin $B_{12}$ study. Poult Sci. (1992) 71:2075-82. doi: $10.3382 / \mathrm{ps} .0712075$

20. Naber EC, Squires MW. Vitamin profiles of eggs as indicators of nutritional status in the laying hen: diet to egg transfer and commercial flock survey. Poult Sci. (1993) 72:1046-53. doi: 10.3382/ps.0721046

21. Giannella RA, Broitman SA, Zamcheck N. Cobalamin uptake by intestinal microorganisms: mechanism and relevance to syndromes of intestinal bacterial overgrowth. J Clin Inves. (1971) 50:1100-7. doi: 10.1172/JCI106581

22. Degnan PH, Taga ME, Goodman AL. Vitamin $B_{12}$ as a modulator of gut microbial ecology. Cell Metab. (2014) 20:769-78. doi: 10.1016/j.cmet.2014.10.002

23. Miki T, Goto R, Fujimoto M, Okada N, Hardt W. The bactericidal lectin regiii beta prolongs gut colonization and enteropathy in the streptomycin mouse model for Salmonella diarrhea. Cell Host Microbe. (2017) 21:195-207. doi: 10.1016/j.chom.2016.12.008

24. Sperandio V. Take your pick: vitamins and microbiota facilitate pathogen clearance. Cell Host Microbe. (2017) 21:130-1. doi: 10.1016/j.chom.2017.01.013

25. Li YX, Wang JK, Sun $\mathrm{H}$, PengYJ, Mao HL, Wu YM, et al. In vitro rumen fermentation and microbial enzyme activities influenced by vitamin $B_{12}$ supplementation in different concentrate to forage ratios. Chin J Anim Nutr. (2012) 24:1888-96. doi: 10.3969/j.issn.1006-267x.2012.10.007

26. Anderson CJ, Clark DE, Mazhar A, Kendall MM, Baumler AJ. Ethanolamine signaling promotes Salmonella niche recognition and adaptation during infection. PLoS Pathog. (2015) 11:e1005278. doi: 10.1371/journal.ppat.1005278

27. Thiennimitr P, Winter SE, Winter MG, Xavier MN, Tolstikov V, Huseby DL, et al. Intestinal inflammation allows Salmonella to use ethanolamine to compete with the microbiota. Proc Natl Acad Sci USA. (2011) 108:17480-5. doi: 10.1073/pnas.1107857108

28. Boran P, Baris HE, Kepenekli E, Erzik C, Dinh DM. The impact of vitamin $\mathrm{B}_{12}$ deficiency on infant gut microbiota. Eur J Pediatr. (2019) 179:385-93. doi: 10.1007/s00431-019-03517-2

29. Zhu X, Xiang S, Feng X, Wang H, Tian S, Xu Y, et al. Impact of cyanocobalamin and methylcobalamin on inflammatory bowel disease and the intestinal microbiota composition. J Agr Food Chem. (2018) 67:916-26. doi: 10.1021/acs.jafc. 8 b05730

30. Xu Y, Xiang S, Ye K, Zheng Y, Feng X, Zhu X, et al. Cobalamin (Vitamin $\mathrm{B}_{12}$ ) induced a shift in microbial composition and metabolic activity in an in vitro colon simulation. Front Microbiol. (2018) 9:2780. doi: $10.3389 /$ fmicb. 2018.02780

31. Hy-Line International. Hy-Line W-36 Performance Standards Manual. (2012). Available online at: http://www.hyline.com/aspx/productsandservices/ managementmanuals.aspx

32. DSM Vitamin Supplementation Guidelines 2016 for Animal Nutrition. Available online at: http://www.dsm.com

33. National Research Council Nutrient Requirements of Poultry. 9th ed. Washington, DC: National Academy Press (1994).

34. Caporaso JG, Kuczynski J, Stombaugh J, Bittinger K, Bushman FD, Costello EK, et al. Qiime allows analysis of high-throughput community sequencing data. Nat Methods. (2010) 7:335-6. doi: 10.1038/nmeth.f.303

35. Gill SR, Pop M, DeBoy RT, Eckburg PB, Turnbaugh PJ, Samuel BS, et al. Metagenomic analysis of the human distal gut microbiome. Science. (2006) 12:1355-9. doi: 10.1371/journal.pone.0231197 
36. Chen H, Jiang W. Application of high-throughput sequencing in understanding human oral microbiome related with health and disease. Front Microbiol. (2014) 5:508-508. doi: 10.3389/fmicb.2014.00508

37. Magoc T, Salzberg SL, FLASH, fast length adjustment of short reads to improve genome assemblies. Bioinformatics. (2011) 27:2957-63. doi: 10.1093/bioinformatics/btr507

38. Edgar RC. search and clustering orders of magnitude faster than BLAST. Bioinformatics. (2010) 26:2460-1. doi: 10.1093/bioinformatics/btq461

39. DeSantis TZ, Rojas M, Dalevi D, Keller K, Huber T, Andersen GL, et al. Greengenes, a chimera-checked $16 \mathrm{~S}$ rRNA gene database and workbench compatible with ARB. Appl Environ Microb. (2006) 72:5069-72. doi: 10.1128/AEM.03006-05

40. Altschul SF, Madden TL, Schaffer AA, Zhang J, Zhang Z, Miller W. Gapped BLAST and PSI-BLAST: a new generation of protein database search programs. Nucleic Acids Res. (1997) 25:3389-402. doi: 10.1093/nar/25.17.3389

41. Huson DH, Mitra S, Ruscheweyh HJ, Weber N, Schuster SC. Integrative analysis of environmental sequences using MEGAN4. Genome Res. (2011) 21:1552-60. doi: 10.1101/gr.120618.111

42. Asnicar F, Weingart G, Tickle TL, Huttenhower C, Segata N. Compact graphical representation of phylogenetic data and metadata with GraPhlAn. PeerJ. (2015) 3:e1029. doi: 10.7717/peerj.1029

43. Zaura E, Keijser BJ, Huse SM, Crielaard W. Defining the Healthy "core microbiome" of oral microbial communities. BMC Microbiol. (2009) 9:259259. doi: 10.1186/1471-2180-9-259

44. White JR, Nagarajan N, Pop M. Statistical methods for detecting differentially abundant features in clinical metagenomic samples. PLoS Comput Biol. (2009) 5:e1000352. doi: 10.1371/journal.pcbi.1000352

45. Langille MGI, Zaneveld J, Caporaso JG, McDonald D, Knights DJ, Reyes A, et al. Predictive functional profiling of microbial communities using 16S rRNA marker gene sequences. Nat Biotechnol. (2013) 31:814-21. doi: $10.1038 /$ nbt.2676

46. Kachana S, Banchasak C, Harnbanchong A. Effect of dietary folate and vitamin $\mathrm{B}_{12}$ on egg composition and liver triglyceride of laying hens at 64 weeks of age. Songklanak J Sci Technol. (2005) 27:789-97.

47. Bunchasak C, Kachana S. Dietary folate and vitamin $B_{12}$ supplementation and consequent vitamin deposition in chicken eggs. Trop Anim Health Pro. (2009) 41:1583-9. doi: 10.1007/s11250-009-9350-7

48. Janist N, Srichana P, Asawakarn T, Kijparkorn S. Effect of supplementing the laying hen diets with choline, folic acid, and vitamin $\mathrm{B}_{12}$ on production performance, egg quality, and yolk phospholipid. Livest Sci. (2019) 223:24-31. doi: 10.1016/j.livsci.2019.02.019

49. Kominato $\mathrm{T}$. Speed of vitamin $\mathrm{B}_{12}$ turnover and its relation to the intestine in the rat. Vitamins. (1971) 44:76-83.

50. Fathi M, Al-Homidan I, Al-Dokhail A, Ebeid T, Abou-Emera O, Alsagan A. Effects of dietary probiotic (Bacillus subtilis) supplementation on productive performance, immune response and egg quality characteristics in laying hens under high ambient temperature. Ital J Anim Sci. (2018) 17:804-14. doi: 10.1080/1828051X.2018.1425104

51. Soltan MA. Effect of dietary organic acid supplementation on egg production, egg quality and some blood serum parameters in laying hens. Int J Poult Sci. (2008) 7:613-21. doi: 10.3923/ijps.2008.613.621

52. Khong C, Sen S, Lee S, Choi Y, Kim KY, Ingale S, et al. Effect of sodium butyrate supplementation on performance, egg quality and bacterial load in the excreta of laying hens. J Anim Res. (2014) 4:141-53. doi: 10.5958/2277-940X.2014.00499.9

53. Pires MF, Leandro NSM, Jacob DV, Carvalho FB, Oliveira HF, Stringhini JH, et al. Performance and egg quality of commercial laying hens fed with various levels of protected sodium butyrate. S Afr J Anim Sci. (2020) 50:758-65. doi: 10.4314/sajas.v50i5.14

54. Wang HH, Shou Y, Zhu X, Xu Y, Shi L, Xiang S, et al. Stability of vitamin $\mathrm{B}_{12}$ with the protection of whey proteins and their effects on the gut microbiome. Food Chem. (2018) 276:298-306. doi: 10.1016/j.foodchem.2018. 10.033

55. Kelly CJ, Alexeev EE, Farb L, Vickery TW, Zheng L, Campbell EL, et al. Oral vitamin $B_{12}$ supplement is delivered to the distal gut, altering the corrinoid profile and selectively depleting Bacteroides in C57BL/6 mice. Gut Microbes. (2019) 10:1-9. doi: 10.1080/19490976.2019.1597667
56. Dong XY, Azzam MMM, Zou XT. Effects of dietary threonine supplementation on intestinal barrier function and gut microbiota of laying hens. Poult Sci. (2017) 96:3654-63. doi: 10.3382/ps/pex185

57. Kumar S, Adhikari P, Oakley BB, Kim WK. Changes in cecum microbial community in response to total sulfur amino acid (TSAA: DL-methionine) in antibiotic-free and supplemented poultry birds. Poult Sci. (2019) 98:5809-19. doi: $10.3382 / \mathrm{ps} / \mathrm{pez} 380$

58. Eeckhaut V, Machiels K, Perrier C, Romero C, Maes S, Flahou B, et al. Butyricicoccus pullicaecorum in inflammatory bowel disease. Gut. (2013) 62:1745-52. doi: 10.1136/gutjnl-2012-303611

59. Wang JX. The gut and hemolymph microbiotas of crustacean, composition, functions and homeostatic regulation. Chin Acta Microbiol Sin. (2018) 58:76072. doi: 10.13343/j.cnki.wsxb.20170407

60. Stephens RW, Arhire LI, Covasa M. Gut microbiota: from microorganisms to metabolic organ influencing obesity. Obesity. (2018) 26:801-9. doi: 10.1002/oby.22179

61. Zhang J, Zhao Y, Ren D, Yang X. Effect of okra fruit powder supplementation on metabolic syndrome and gut microbiota diversity in high fat diet-induced obese mice. Food Res Int. (2020) 130:108929. doi: 10.1016/j.foodres.2019.108929

62. Guilloteau P, Martin L, Eeckhaut V, Ducatelle R, Zabielski R, Van Immerseel F. From the gut to the peripheral tissues: the multiple effects of butyrate. Nutr Res Rev. (2010) 23:366-84. doi: 10.1017/S0954422410000247

63. Bedford A. and Gong J. Implications of butyrate and its derivatives for gut health and animal production. Anim Nutr. (2018) 4:151-9. doi: 10.1016/j.aninu.2017.08.010

64. Antongiovanni M, Buccioni A, Petacchi F, Leeson S, Minieri S, Martini A. Butyric acid glycerides in the diet of broiler chickens: effects on gut histology and carcass composition. Ital J Anim Sci. (2007) 6:19-26. doi: 10.4081/ijas.2007.19

65. Leylabadlo HE, Ghotaslou R, Feizabadi MM, Farajnia S, Moaddab SY, Ganbarov $\mathrm{K}$, et al. The critical role of Faecalibacterium prausnitzii in human health: an overview. Microb Pathogenesis. (2020) 149:104344. doi: 10.1016/j.micpath.2020.104344

66. Lopezsiles M, Duncan SH, Garciagil LJ, Martinezmedina M. Faecalibacterium prausnitzii: from microbiology to diagnostics and prognostics. ISME J. (2017) 11:841-52. doi: 10.1038/ismej.2016.176

67. Ferreira-Halder CV, Faria AVS, Andrade SS. Action and function of Faecalibacterium prausnitzii in health and disease. Best Pract Res Clin Gastroenterol. (2017) 31:243-8. doi: 10.1016/j.bpg.2017.09.011

68. Trachsel J, Humphrey S, Allen HK. Butyricicoccus porcorum sp. nov., a butyrate-producing bacterium from swine intestinal tract. Int J Syst Evol Microbiol. (2018) 68:1737-42. doi: 10.1099/ijsem.0.002738

69. $\mathrm{Mu} \mathrm{Q}$, Tavella VJ, Luo XM. Role of Lactobacillus reuteri in human health and diseases. Front Microbiol. (2018) 9:757. doi: 10.3389/fmicb.2018. 00757

70. Koenen ME, Heres L, Claassen E. and Boers WJA. Lactobacilli as probiotics in chicken feeds. Biosci. Microflora. (2002) 21:209-16. doi: 10.12938/bifidus1996.21.209

71. Zhang S, Zhong G, Shao D, Wang Q, Hu Y, Wu TX, et al. Dietary supplementation with Bacillus subtilis promotes growth performance of broilers by altering the dominant microbial community. Poult Sci. (2021) 100:3. doi: $10.1016 /$ j.psj.2020.12.032

72. Stackebrandt E, Hespell RB. The family Succinivibrionaceae. In: Rosenberg E, DeLong EF, Lory S, Stackebrandt E, Thompson F, editors. The Prokaryotes. Berlin; Heidelberg: Springer (2006). p. 639-48. doi: 10.1007/0-387-30743-5_20

73. Hu Y, Wang LD, Shao D, Wang Q, Wu YY, Han YM, et al. Selective and reshaped early dominant microbial community in the cecum with similar proportions and better homogenization and species diversity due to organic acids as AGP alternatives mediate their effects on broilers growth. Front Microbiol. (2020) 10:2948. doi: 10.3389/fmicb.2019. 02948

74. Qiu YL, Kuang XZ, Shi XS, Yuan XZ, Guo RB. Paludibacter jiangxiensis sp. nov a strictly anaerobic, propionate-producing bacterium isolated from rice paddy. Field Arch Microbiol. (2014) 196:149-55. doi: 10.1007/s00203-013-0951-1 
75. Koh A, De Vadder F, Kovatcheva-Datchary P, Bäckhed F. From dietary fiber to host physiology: short-chain fatty acids as key bacterial metabolites. Cell. (2016) 165:1332-45. doi: 10.1016/j.cell.2016. 05.041

76. Liu T, Tang J, Feng F. Medium-chain $\alpha$-monoglycerides improves productive performance and egg quality in aged hens associated with gut microbiota modulation. Poult Sci. (2020) 99:7122-32. doi: 10.1016/j.psj.2020.7.049

77. Li Z, Lin Z, Lu Z, Feng Z, Ying Z. Coix seed improves growth performance and productivity in post-weaning pigs by reducing gut $\mathrm{pH}$ and modulating gut microbiota. AMB Express. (2019) 9:115-29. doi: 10.1186/s13568-0190828-Z

78. Htay H, Cho Y, Ascoe PM, Hawley CM, Johnson DW. Outcomes of Acinetobacter peritonitis in peritoneal dialysis patients: a multicenter registry analysis. Peritoneal Dial Int Perit Dial Int. (2018) 38:257-65. doi: $10.3747 /$ pdi.2017.00199

79. Iqbal SP, Kakepoto GN, Iqbal SP. Gastrointestinal abnormalities in vitamin $\mathrm{B}_{12}$ deficient patients with megaloblastic anemia. J Coll Physicians Surg Pak. (2009) 19:672-3. doi: 10.2009/JCPSP.672673
Conflict of Interest: The authors declare that the research was conducted in the absence of any commercial or financial relationships that could be construed as a potential conflict of interest.

Publisher's Note: All claims expressed in this article are solely those of the authors and do not necessarily represent those of their affiliated organizations, or those of the publisher, the editors and the reviewers. Any product that may be evaluated in this article, or claim that may be made by its manufacturer, is not guaranteed or endorsed by the publisher.

Copyright (c) 2021 Wang, Bai, Yang, Wu and Li. This is an open-access article distributed under the terms of the Creative Commons Attribution License (CC BY). The use, distribution or reproduction in other forums is permitted, provided the original author(s) and the copyright owner(s) are credited and that the original publication in this journal is cited, in accordance with accepted academic practice. No use, distribution or reproduction is permitted which does not comply with these terms. 